\title{
Small multi-band microstrip antenna for wireless applications
}

\author{
Mohammad Tariqul Islam ${ }^{1 a)}$, Ahmed Toaha Mobashsher ${ }^{2}$, \\ and Norbahiah Misran ${ }^{2}$ \\ ${ }^{1}$ Institute of Space Science (ANGKASA) Universiti Kebangsaan Malaysia \\ Bangi, Selangor, Malaysia \\ ${ }^{2}$ Dept. of Electrical, Electronic and Systems Engineering Universiti Kebangsaan \\ Malaysia Bangi, Selangor, Malaysia \\ a) titareq@yahoo.com
}

\begin{abstract}
A simple microstrip line fed antenna with thin substrate is proposed in this letter for multi-band wireless applications. The multi-band characteristic was achieved by overlapping an annular slot antenna with two concentric fan shaped patches. The antenna demonstrates three wide impedance bandwidths (VSWR $\leq 2$ ) of $36.3,63.4$ and $25.5 \%$ with stable polarization and radiation characteristics.
\end{abstract}

Keywords: multi-band antenna, wideband antenna

Classification: Microwave and millimeter wave devices, circuits, and systems

\section{References}

[1] B. Sanz-Izquierdo, J. C. Batchelor, R. J. Langley, and M. I. Sobhy, "Single and double layer planar multiband PIFAs," IEEE Trans. Antennas Propag., vol. 54, pp. 1416-1422, 2006.

[2] M. T. Islam, A. T. Mobashsher, and N. Misran, "A novel feeding technique for a dual band microstrip patch antenna," IEICE Trans. Commun., vol. E93-B, pp. 2455-2457, 2010.

[3] J.-S. Chen, "Dual-frequency annular-ring slot antennas fed by CPW feed and microstrip line feed," IEEE Trans. Antennas Propag., vol. 53, pp. 569573, 2005.

[4] J.-S. Row, "Dual-frequency circularly polarised annular-ring microstrip antenna," Electron. Lett., vol. 40, pp. 153-154, 2004.

[5] X. L. Bao and M. J. Ammann, "Microstrip-fed dual-frequency annularslot antenna loaded by split-ring-slot," IET Microw. Antennas Propag., vol. 3, pp. 757-764, 2009.

[6] X. L. Bao and M. J. Ammann, "Small patch/slot antenna with $53 \%$ input impedance bandwidth," Electron. Lett., vol. 43, pp. 146-147, 2007.

[7] Y.-F. Lin, H.-M. Chen, and S.-C. Lin, "A new coupling mechanism for circularly polarized annular-ring patch antenna," IEEE Trans. Antennas Propag., vol. 56, pp. 11-16, 2008. 


\section{Introduction}

Microstrip antennas are widely used in various wireless applications owing to their advantageous features in terms of thin profile, low cost, lightweight, easy manufacturability and conformability. Hence they have experienced to be the center of attention for a long time in the research of antennas and wireless propagation. However, they possess the intrinsic limitation of narrow impedance bandwidth (nearly $5 \%$ ) when fabricated on thin substrates. In the reported literature [1], a double layer PIFA antenna is proposed which supports most of the wireless communications frequency bands. But the use of multilayer PIFA structure makes the design complex and bulky. However, recently reported novel feeding technique also lacks in terms of wide bandwidth [2]. In the past few years, annular ring and annular slot antennas has been reported to be favorable in realizing multi-band characteristics achieving good radiation characteristics with reduced profile [3, 4]. Some dual-frequency antennas have been realized by a split-ring-slot loaded on annular-slot antenna [5]. These antennas are not miniaturized and can not achieve a good impedance bandwidth in the lower frequency bands. But the antenna proposed in [6] provides broadband performance on thin substrate. However, still there is less number of researches concerning multi-band and wideband antenna with small aperture.

Recently, a fan-shaped patch along with cylindrical ceramic dielectric has been used as a new coupling mechanism for annular-ring antenna [7]. Nevertheless, the antenna still can not achieve wideband characteristics. This letter is an effort to employ fan-shaped patches in order to couple with annular ring slot antenna to produce multi-band and wideband characteristics with thin substrate. The small antenna achieves three wide impedance bands namely 36, 64 and 25\% compared to the center frequencies of 1.075, 2.05 and $5.33 \mathrm{GHz}$ for the various applications of wireless communications mentioned in Table I.

Table I. Applications of the Proposed Antenna

\begin{tabular}{|l|l|}
\hline System & Frequency Bands (MHz) \\
\hline GSM 900 & $880-960$ \\
GSM 1900 & $1850-1990$ \\
DETC & $1880-1900$ \\
UMTS/W-CDMA & $1920-2170$ \\
Mobile WiMAX & $2110-2200,2300-2400,2500-2690$ \\
WLAN & $2400-2485,5150-5350,5750-5850$ \\
Bluetooth & $2400-2497$ \\
RFID & $902-928,2400-2483.5,5725-5875$ \\
\hline
\end{tabular}

\section{Antenna design}

Fig. 1 (a) shows the geometry of the proposed multi-band antenna. It is printed on FR4 substrate of thickness, $\mathrm{h}=1.52 \mathrm{~mm}$ and relative permittivity, $\varepsilon_{r}=4.0$, loss tangent $\tan \delta=0.018$. On the ground plane an annular ring slot is cut with inner and outer radii of $R_{1}$ and $R_{2}$. A $50 \Omega$ coaxial 
probe feeds a microstrip line, etched on the opposite side of the ground plane with dimension of $\mathrm{L}_{\mathrm{f}}$ and $\mathrm{W}_{\mathrm{f}}$. Two concentric, namely small and big fanshaped patches of angles and radii of $\theta_{1}, \theta_{2}$ and $R_{2}, R_{3}$ respectively are overlapped on the circular disk of the annular slot along the microstrip line feeding. The dimensions of the fan-shaped patches are mostly reliable to achieve multi-band and wideband characteristics with low profile. For this new antenna structure, the lower operating frequency is determined mainly by outer annular-ring dimension. The second operating band is constructed by three resonating frequencies; this band can be attributed to the inner circular patch dimension and the big fan-shaped patch. On the other hand, the higher band which covers whole $5 \mathrm{GHz}$ WLAN is dependent on both of the fan-shaped patch structures, namely position, radii and angles of the fanshaped patches. Broad impedance band-widths can be obtained by adjusting the dimensions of the feeding line and the shape of the ground plane. After a thorough parametric study the total structure of the antenna is defined by $80 \times 80 \times 1.6 \mathrm{~mm}^{3}$ which is smaller than conventional annular slot antennas; this shape is equivalent to $0.23 \lambda_{0} \times 0.23 \lambda_{0} \times 0.005 \lambda_{0}$, where $\lambda_{0}$ is the free space wavelength at the cutoff frequency of its lower operating bandwidth. Fig. 1 (b) shows the effects of the fan-shaped patches on the VSWR of the antenna. As realized from the plots, the multi-band characteristics of the antenna vitally depend on the proper optimization of the fan-shaped patches which simultaneously increases the wideband behavior. Optimized design parameters of the multi-band antenna are: $R_{1}=13 \mathrm{~mm}, R_{2}=25 \mathrm{~mm}$, $\mathrm{R}_{3}=35 \mathrm{~mm}, \mathrm{R}_{4}=37 \mathrm{~mm}, \mathrm{~L}_{f}=29 \mathrm{~mm}, \mathrm{~W}_{f}=4 \mathrm{~mm}, \mathrm{~L}=80 \mathrm{~mm}, \mathrm{~W}=$ $80 \mathrm{~mm}, \theta_{1}=120^{\circ}, \theta_{2}=50^{\circ}$. The feeding of the antenna is selected to be symmetrical along the line centered at the mid-point of y-axis length of the antenna, in order to achieve good impedance matching and symmetrical excitement of the middle fan shaped circular sectors, which are also set along the same line.

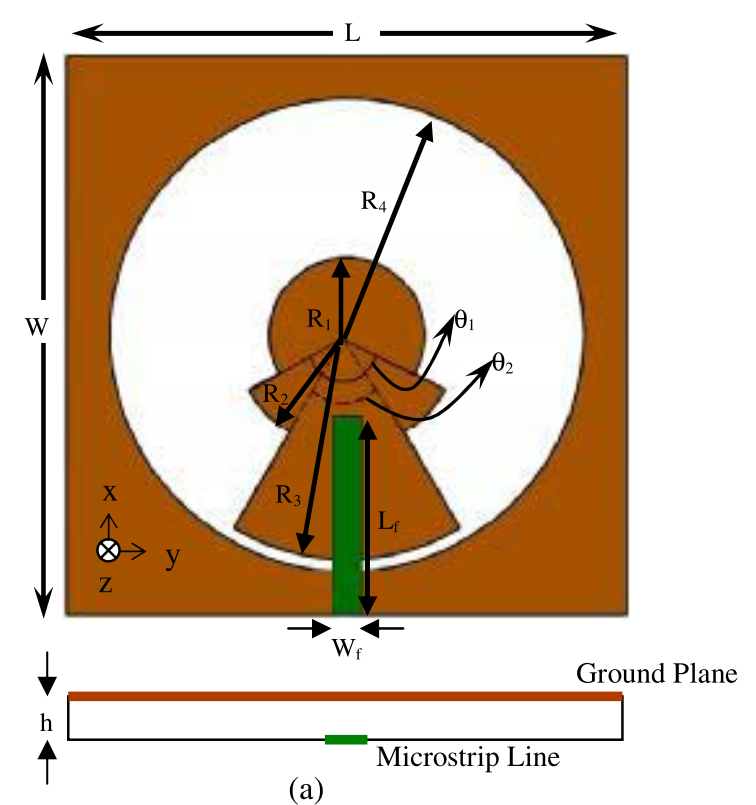




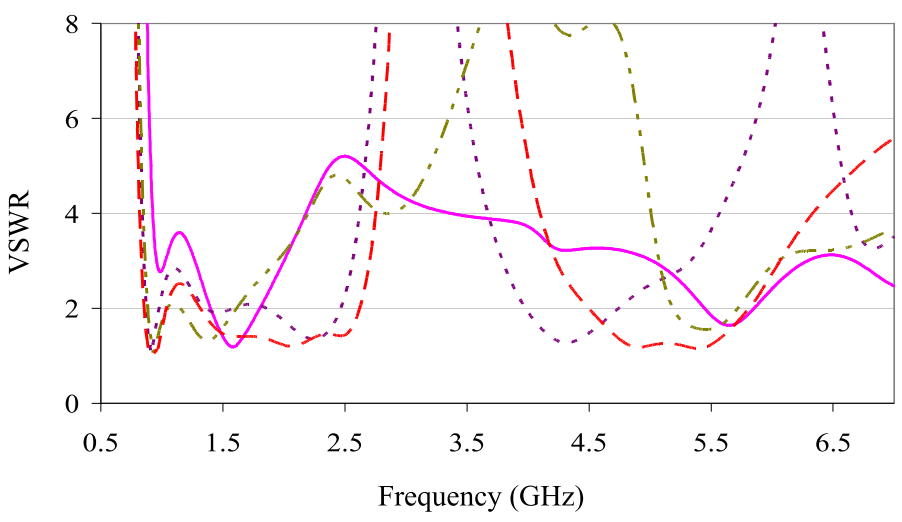

— Without Big \& Small Fan-shaped Patch

- - Without Small Fan-shaped patch

- - Without Big Fan-shaped patch

- - Proposed antenna

(b)

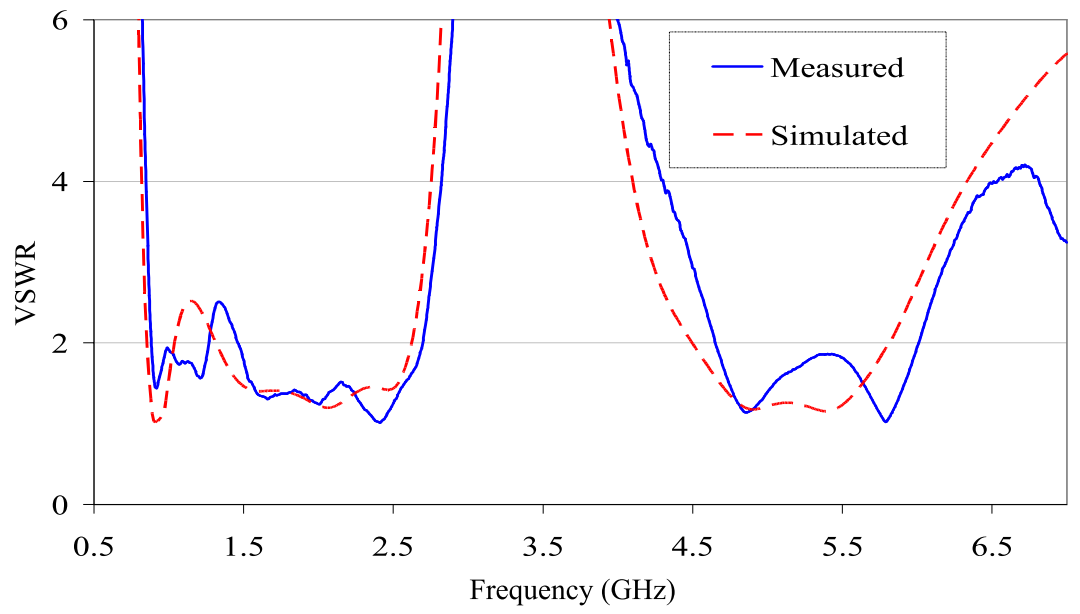

(c)

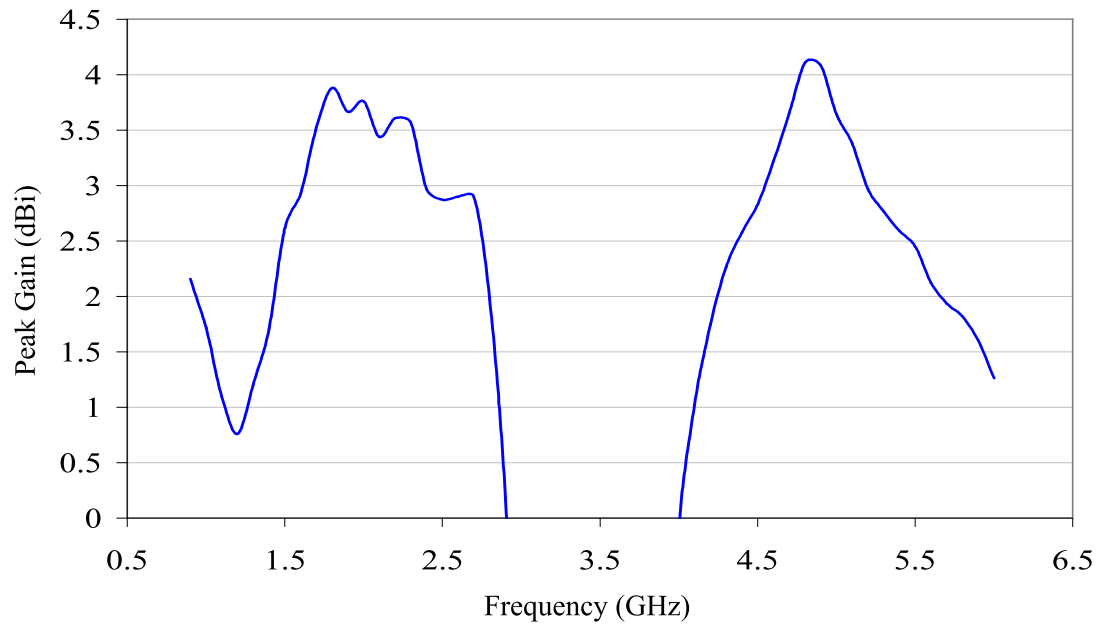

(d)

Fig. 1. (a) Schematic diagram of proposed antenna, (b) Effect on VSWR for the fan-shaped patches, (c) Measured and simulated VSWR, (d) Measured peak antenna gain 


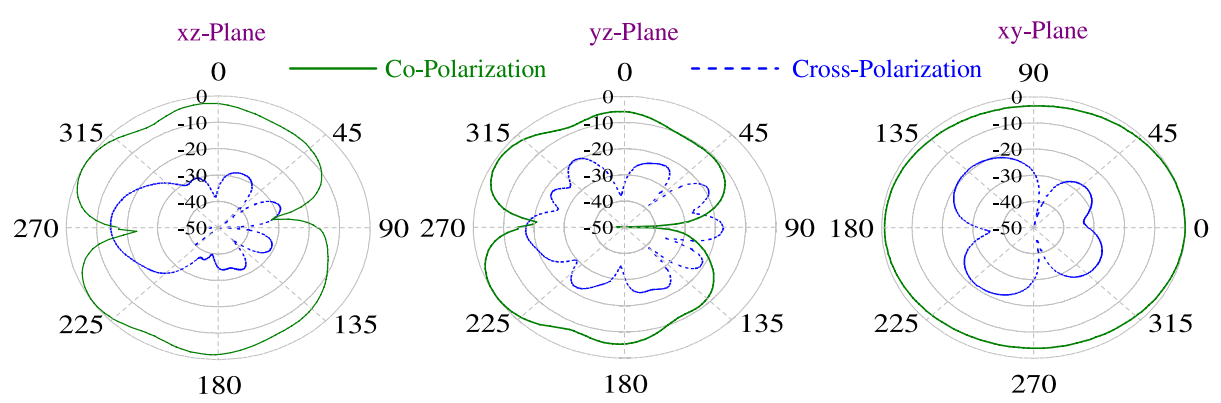

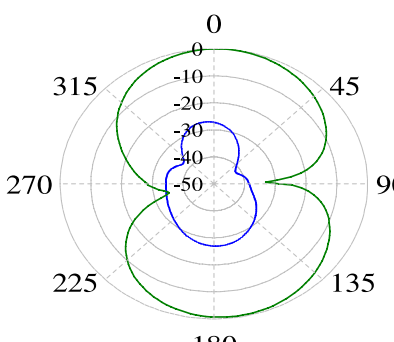

180

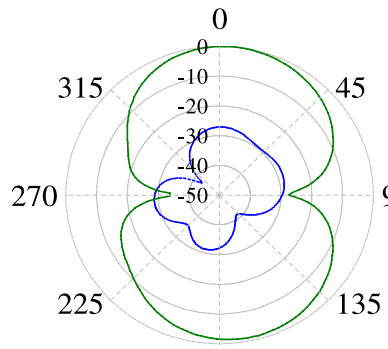

180

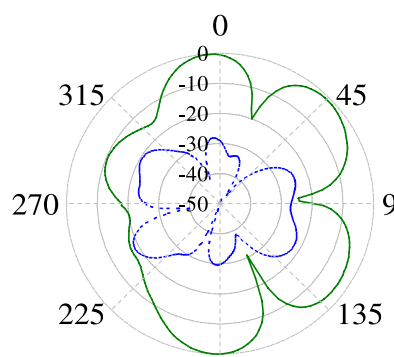

180

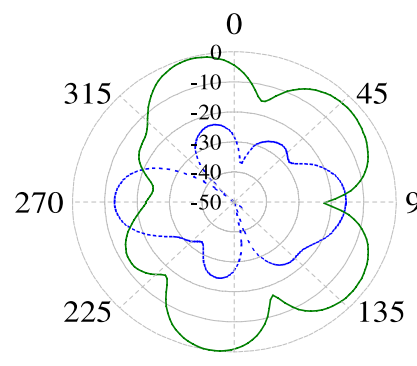

180

(a)
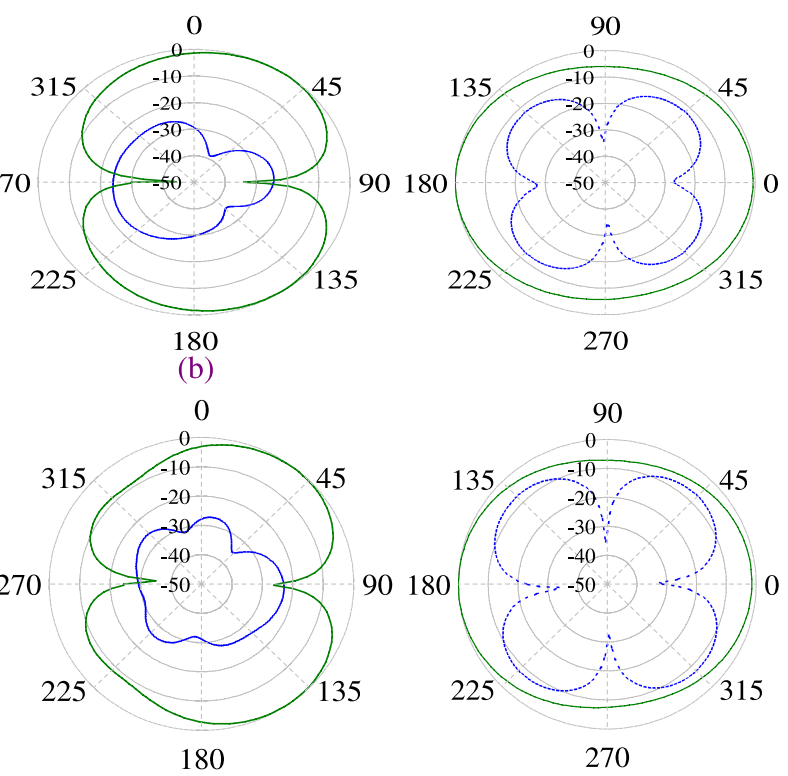

(c)

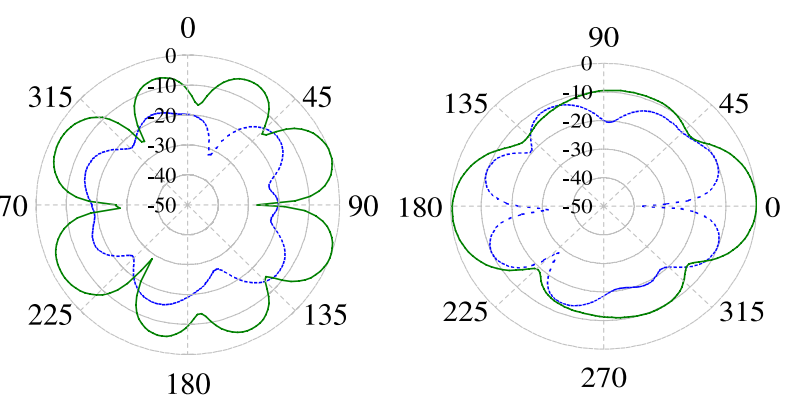

(d)
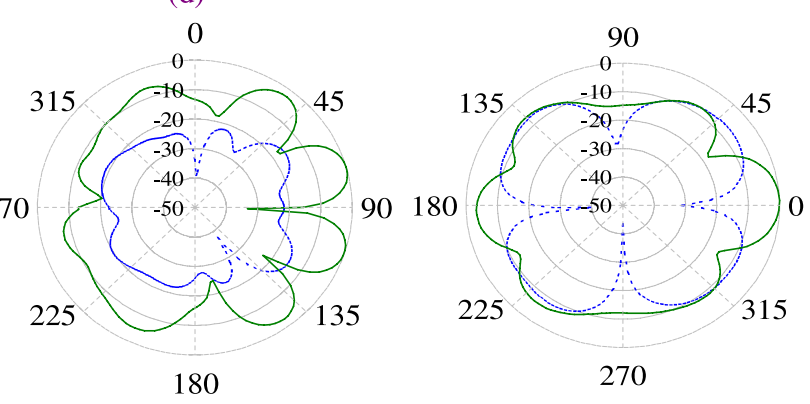

(e)

Fig. 2. Measured radiation patterns for $x z, y z$ and $x y-$ planes at (a) $900 \mathrm{MHz}$, (b) $2 \mathrm{GHz}$, (c) $2.45 \mathrm{GHz}$, (d) $5.2 \mathrm{GHz}$, (e) $5.8 \mathrm{GHz}$ 


\section{Results \& discussion}

According to the optimized design specifications, an antenna is prototyped and measured. Fig. 1(c) shows the measured and simulated VSWR of the fabricated antenna. As seen from the plotted graphs, the antenna produces three resonating bands. The antenna achieves wide bands (VSWR $\leq 2$ ) of $390 \mathrm{MHz}$ (0.88 to $1.27 \mathrm{GHz}), 1.3 \mathrm{GHz}(1.46$ to $2.70 \mathrm{GHz}$ ) and $1.36 \mathrm{GHz}$ (4.65 to $6.01 \mathrm{GHz}$ ) in the three operating bands respectively. The bands are accordingly equivalent to $36.3,63.4$ and $25.5 \%$ with respect to the center frequencies of $1.075,2.05$ and $5.33 \mathrm{GHz}$. There is however some difference between the simulated and measured plots, especially in the lower frequency band. This is because of the assumption of lossless $50 \Omega$ SMA connector and inconsideration of the dielectric and conductor losses in the simulation [7].

Fig. 1 (d) shows the measured peak antenna gains within the wide operating bands. From Fig. 1 (d), the gain variations are observed to be less than $0.5 \mathrm{~dB}$ with a maximum gain of about $2.2 \mathrm{dBi}$ in the GSM 900 band. Also, the gain variations in the second operating band can be less than $3 \mathrm{~dB}$ with a maximum antenna gain of about $3.9 \mathrm{dBi}$ in the GSM 1900 and UMTS bands. In the higher band the gain fluctuation is less than $1.4 \mathrm{dBi}$ with a maximum gain of $3 \mathrm{dBi}$ is observed in the measured gain curve.

Fig. 2 depicts the measured radiation patterns of the prototyped antenna. As expected, the antenna exhibits a bidirectional radiation pattern due to the fact that there is no reflector used in the wideband antenna [6]. From the measured plots, it is obvious that the operating frequencies across the impedance bandwidth of this antenna have the same polarization planes and similar broadside radiation patterns. However at the $5 \mathrm{GHz}$ band, there are some nulls observed due to the occurred higher harmonics. Otherwise, it is seen that the radiation patterns obtained are stable throughout each of operating bands.

\section{Conclusion}

In this paper an annular slot antenna loaded with two concentric fan-shaped patches is proposed and investigated successfully as an effective way to achieve a wider bandwidth in annular slot antennas with small aperture. The prototyped antenna exhibits three major operating bands with impedance bandwidths of 36.3, 63.4 and $25.5 \%$ accordingly, with good radiation characteristics. The antenna design can be used in various wireless applications and services to realize a compact antenna system where limited size is a major requirement. 